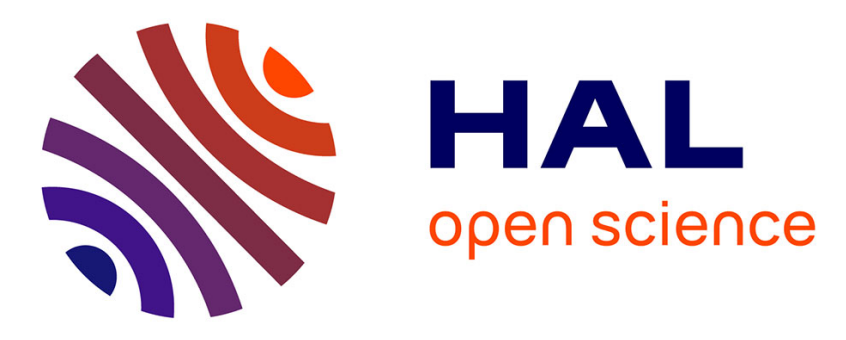

\title{
Predictive factors of the survival of women with invasive breast cancer in French Guiana: the burden of health inequalities
}

Tristan Roué, Sylvain Labbé, Sophie Belliardo, Juliette Plenet, Maylis Douine, Mathieu Nacher

\section{To cite this version:}

Tristan Roué, Sylvain Labbé, Sophie Belliardo, Juliette Plenet, Maylis Douine, et al.. Predictive factors of the survival of women with invasive breast cancer in French Guiana: the burden of health inequalities. Clinical Breast Cancer, 2016, 10.1016/j.clbc.2016.02.017 . hal-01288657

\section{HAL Id: hal-01288657 \\ https://hal.science/hal-01288657}

Submitted on 15 Mar 2016

HAL is a multi-disciplinary open access archive for the deposit and dissemination of scientific research documents, whether they are published or not. The documents may come from teaching and research institutions in France or abroad, or from public or private research centers.
L'archive ouverte pluridisciplinaire HAL, est destinée au dépôt et à la diffusion de documents scientifiques de niveau recherche, publiés ou non, émanant des établissements d'enseignement et de recherche français ou étrangers, des laboratoires publics ou privés. 


\section{Predictive factors of the survival of women with invasive breast cancer in French Guiana: the burden of health inequalities}

\section{Tristan Roué*, Sylvain Labbé*§, Sophie Belliardo*, Juliette Plenet*,Maylis Douine $¥$,Mathieu Nacher $† \ddagger$}

From the *Cancer registry of French Guiana; †Centre d'Investigation Clinique, Epidemiologie Clinique Antilles Guyane, ‡Centre Hospitalier Andree Rosemon, Cayenne; §Service d'Anatomie Pathologique.

Address correspondence and reprint requests to Tristan Roué, Registre des Cancers de Guyane, Cayenne, French Guiana.

E-mail: tristan.roue@gmail.com sylvain.labbe@ch-cayenne.fr registre-guyane@wanadoo.fr plenet.juliette@orange.fr mdouine@yahoo.fr

mathieu.nacher@ch-cayenne.fr

Corresponding author: Tristan Roué, 30 av. Du Général de Gaulle, Saint-Mandé, France, tristan.roue@gmail.com,06.61.09.16.19.

Keywords : Breast cancer, Survival, Immigrant, South America

Word count : 2278 


\section{ABSTRACT}

This study aimed to compare the relative survival of patients with invasive breast cancer between women from French Guiana (a French territory in South America) and metropolitan France. No study hadever compared survival of breast cancer on the basis of immigrant status in France. Our study underlined that access to care for migrants is challenging whichwgenerates health inequalities.

\section{Background}

The prognosis of breast cancer in French Guiana is worse than in France with 23 deaths per 100 incident cases against 17 per 100 in metropolitan France.

This study aimed to compare relative survival of patients with invasive breast cancer (IBC) between women from French Guiana and metropolitan France and to determine risk factors influencing breast cancer survival in French Guiana.

\section{Materials and methods}

Data were collected from the Cancer registry of French Guiana. We comparedthe relative survival of women with IBC between French Guiana and metropolitan France. We used Cox's proportional hazard regression to evaluate the effect of prognostic factors on cancer-specific mortality in French Guiana.

\section{Results}

We included all 269 cases of IBC in women diagnosed in French Guiana between 2003 and 2009. The overall 5year relative survival rate of patients with IBC was $79 \%$ in French Guiana and $86 \%$ in metropolitan France. The place of birth (foreign country versus French territory), the tumor stage at the time of diagnosis, the mode of diagnosis (symptoms versus screening), the presence of hormone receptors in the tumor and the histologic type were the variables associated with survival differences. None of the other study variables were significantly associated with prognosis.

\section{Conclusion}

Access to care for migrants is challenging,which leads to health inequalities. Early detection through prevention programs is crucial to increaseIBC survival notably for foreign-born patients.

\section{INTRODUCTION}

Breast cancer is the most common type of cancer and the most common cause of cancer-related death in women worldwide. ${ }^{1}$ Although breast cancer incidence is much higher in most developed countries than in many developing countries, mortality rates are proportionally higher in less developed regions of the world, notablyin South America. ${ }^{2,}$ French Guiana is a French territory located on the Guiana shield in South America.Despite a high GDP per capita close to that of France, the incidence of breast cancer in French Guiana is on par with the overall incidence in South America and markedly lower than in France. ${ }^{4}$ To reduce the burden of breast cancer and understand differences in cancer prognosis between different areas it is important to identify predictive factors for survival.

Stage of disease at diagnosis is the most important prognostic factorforbreast cancer. ${ }^{5,6}$ Overall, early detection, screening and therapeutic improvements havesignificantly reduced breast cancer mortality. ${ }^{7-9}$ Despite this evidence,studies in New Zealand and USAhave shownthat immigrant women were less likely than nonimmigrant women to report having had a mammogram in the past 2 years or to be diagnosed at an early stage of disease. ${ }^{10,11}$ In France, C. Rondet and colleagues, ${ }^{12}$ showed that being a foreigner or of immigrant origin was a risk factor for being screened for cancer too late or never and that this gradient persisted after adjusting for socioeconomic characteristics. French Guiana attracts numerous immigrants from South America and the Caribbean who migrate in search of better socioeconomic opportunities. Thus, $30 \%$ of the population consists of immigrantsversus $8 \%$ in metropolitan France. ${ }^{13}$ Immigrants have access to health insurance, butin practice this may be somewhat complicated. Particularly, cases requiring specialized care are evacuated towards metropolitan France or Martinique for treatment.Immigrants mayexperience a number of informal barriers to hospital care related to language, unfamiliarity, and cultural factors in a socialised health-care system. ${ }^{14}$ It therefore seems important to study survival differences between immigrants and French-born patients.Indeed, in France no study has ever compared breast cancer survival between immigrant and French women.

In the present study, we focussed on female breast cancer survival in French Guiana and aimed to determine whether different levels of breast cancer risk between metropolitan France and French Guiana, ${ }^{4}$ also implieddifferences in survival. Wedetermined risk factors influencing breast cancer survival in French Guiana taking the immigrant status into account.

\section{MATERIALS AND METHODS}




\section{Ethical statement}

This study used data from the Cancer Registry of French Guiana housed by the Regional Union of health care professionals (URPS). It has been officially certified by the Comité National des Registres (CNR) an emanation of the INSERM (National Institute for Medical Research) and the INVS (National Institute for Epidemiologic Surveillance and Alert, French CDC) in 2010 and 2012. Every three years the registry undergoes a quality audit by the Comite d'Evaluation des Registres.

The registry has a scientific board and an ethical review board. The database has national regulatory approval by the Comission Nationale Informatique et Libertés (CNIL). All confidential information is encoded, protected by security systems and destroyed when no longer needed. No published results can allow the identification of patients. Participants gave written informed consent to the Cancer registry for the collection and use of their medical data.

\section{Data source}

Data coding strictly follows the procedures of the FRANCIM (Réseau Français des Registres de Cancer) \& ENCR (European Network of Cancer Registries) network.

\section{Study population and register linkages}

This retrospective study was based on breast cancer cases diagnosed in persons living in French Guiana at the time of diagnosis from January $1^{\text {st }}, 2003$ to December $31^{\text {st }}, 2009$. The capture-recapture method was used to estimate the completeness of cancer registration. ${ }^{15} \mathrm{We}$ estimated that 6 cases of breast cancer were missed between 2003 and 2009: completeness was estimated to be $96 \%$.

\section{Prognostic factors}

The following socio-demographic factors were studied: age ( $<35$ years [reference group], 35-49 years, 50-64 years, 65-74 years, $\geq 75$ years); place of birth divided in two categories ("France" identifying patients born within all French regions [reference group] and "foreign country" defining patients born outside the Frenchterritory). In addition, information on thetumor were collected by the registry: tumor stage ("localized" T1-3N0M0 [reference group], "regional spread" T1-3N+M0, i.e. axillary lymph nodes that were positive for cancer on histological examination, "local spread" T4NxM0, "distant" M1); we could not distinguish mass screening from selective/opportunistic screening, thus themode of diagnosis was separated in two categories only (screening [reference group], diagnosis after symptoms); scarff-Bloom-Richardson (SBR) classification hadthree categories ("low" grade 1 [reference group], "intermediate" grade 2, "high" grade 3); histological type hadtwo categories (papillary-medullary-mucinous and tubular carcinoma [reference group], infiltrating duct carcinoma); hormone receptor status hadtwo categories because we could not distinguish both estrogen and progesterone in the data base ("positive" meant either estrogen or progesterone receptors were positive [reference group], "negative" meant both estrogen and progesterone receptors were negative); study period (2003-2005 [reference group], 2006-2009). HER2/neu expression was not available. The delays between the date of diagnosis and the date of first treatment were unknown for $36 \%$ of women, thusthis variable wasnot included in the analyses.

\section{Follow-up}

The breast cancer-specificsurvival was estimated byfollowing-up all cases untilDecember $31^{\text {st }}, 2013$. The vital status of patients was checked regularly. The follow-up for the vital status can be done actively, through the RNIPP (Repertoire National d'Identification des Personnes Physiques) an emanation of the Insee (Institut national de la statistique et des études économiques), or passively, by matching death certificates at city hall.

\section{Statistical analysis}

For cancer cases net survival was the probability of survival in the hypothetical scenario where the studied cancer wasthe only possible cause of death.

To compare breast cancer survival between French Guiana and metropolitan France, net survival durations were obtained using the new Pohar-Perme estimator of the net cumulative rate. ${ }^{16}$ Age-standardized net survival estimates were calculated using international cancer standard weights. ${ }^{16,17}$ We compared two estimates at a given time with a classical Z-test.

Cause-specific survival isanother estimator of net survival. Cox proportional hazard models were used to estimate crude and adjusted mortality hazard ratios to compare breast cancer-specific survival according to prognostic factors. The underlying time scale was the time since diagnosis. The failure event was death due to breast cancer. Sixpatients without follow-up were excluded. No patients were notified with only a death certificate. Associated variables with $p$-values $<0.05$ in multivariate analyseswere considered statistically significant. Nonlinearity of continuous variables (age and study period) were assessed using a cubic spline term. ${ }^{18}$ The proportional hazards assumption for all the covariates was tested and validated by Schoenfeld 
residuals. Interactions between variables were also examined and considered if $p<0.1$ in multivariate analyses.

To avoid loss of information and potentially biased estimates resulting from missing data in Cox analyses, we imputed missing values usingMultivariate Imputation by Chained Equation under missing-at-random (MAR) assumptions. ${ }^{19}$ All associated variables with $p<0.2$ in univariate analyses were also included in the series of chained equations. $^{20}$

All data analyses were performed using Stata/MP version 11.1 for Windows (StataCorp, USA).

\section{RESULTS}

Between 2003 and 2009, there were 275 new cases of breast cancer. Sixpatients without follow-up were excluded thus 269 patients were included in this study.The median age at diagnosis was 52 years (interquartile range: $44-60$ years), the youngest patient was 27 years old and the oldest was 94 years old. Table 1 presents patient and tumor characteristics. Overall, information on socio-demographic and tumor characteristics were available for $200(74 \%)$ of the patients. Information on age, mode of diagnosis, tumor stage at diagnosis, SBR classification, histological type and hormone receptor status were available for $100 \%, 89.2 \%, 88.9 \%, 82.9 \%$, $92.2 \%$ and $83.3 \%$ of the patients, respectively. The proportion of patient born outside France was $34.6 \%$. These immigrants originated from Haiti (39\%), Brazil (17\%), Suriname (13\%), Saint Lucia (7\%), Guyana (7\%), Anguilla (4\%), Dominican Republic (3\%), China (2\%) and others countries (8\%).

Table 2 shows age-standardized 1, 3, 5-year net survival of invasive breast cancer patients in French Guiana and in metropolitan France. The age-standardized 1-year net survival of women with invasive breast cancer was not significantly different between French Guiana and metropolitan France. The 3-year net survival was $85 \%$ in French Guiana, compared to $91 \%$ for metropolitan France. This difference was most pronounced five years after the breast cancer diagnosis. The 5-year net survival was 79\% in French Guiana versus $86 \%$ in metropolitan France $(p<0.05)$.Nevertheless, In French Guiana, the overall 5-year net survival rate of foreign-born patients and patients born on the French territory were respectively $62 \%$ and $87 \%$. In French Guiana, women born on aFrench territory (including French Guiana) had the same survival rate as in metropolitan France (not shown in the table 2).

Table 3 shows the hazard ratio (HR) of death by age, place of birth, mode of diagnosis, study period and tumor characteristics.A total of 65 women $(24 \%)$ died before the $31^{\text {st }}$ December 2013 and 60 deaths were attributed to breast cancer. In univariate analyses (complete-cases only)all variables except study period were associated with mortality $(p<0.25)$. In multivariate analyses (after imputation), place of birth, mode of diagnosis, tumor stage at diagnosis, histological type and hormone receptor status remained independently associated with breast cancerspecific survival $(p<0.05)$. After adjusting for these factors, age and SBR classification were no longer associated with specific survival.

\section{DISCUSSION AND CONCLUSIONS}

This high resolution study presents survival data of breast cancer patients from French Guiana for the first time. The present study showed that the overall relative survival rate among women with invasive breast cancer in French Guiana was lower than among women in metropolitan France. Regression analysis revealed mode of diagnosis, tumor stage at diagnosis, histological type and hormone receptor status as independent prognostic factors associated with breast cancer-specific survival in French Guiana. The novel result of the present study was that there was a significant difference in breast cancer survival between women in French Guiana according to their immigrant status.

Histological type and hormone receptor status are commonly prognostic factors of breast cancer with regard to disease recurrence and survival. ${ }^{51}$ The main limitation is that we only had the combined hormone effects on survival. Nevertheless our study showed as in previous studies, ${ }^{22}$ that hormone receptor status was an independent prognostic factor of breast cancer survival. Clinical trials have shown that a large proportion of the survival advantage experienced by patients with hormone receptor-positive tumors compared to patients with hormone receptor-negative tumors may be due to the use of hormonal therapy. ${ }^{22,23}$

The mode of diagnosis was consistently associated with mortality among women diagnosed on the basis of clinical symptoms. Since 2004, mass organized screening was initiated throughout the French territory. All women aged $50-74$ years are concerned by this every 2 years.

As in other studies, the most important feature in the multivariate model was stage at diagnosis. ${ }^{24}$ ${ }^{25}$ Unsurprisingly, early stage invasive breast cancer hada better prognosis than later stage cancer.

Based on ethical and ideological considerations, the mortality of immigrants in France has been scarcely studied. $^{26}$ Our study revealeda 1.80 -fold difference in HR between women born in France and foreign born women after adjusting for stage at diagnosis and other prognostic factors.Moreover the difference in net survival between French Guiana and metropolitan France could in fact have reflectedthelower net survival rate among foreign-born patients in French Guiana than among patients born on the French territory. Indeed, in French 
Guiana, women born on the French territory had the same survival rate as in metropolitan France. Previous studies showed that immigrants who experience a language barrier are generally more stressed, which can lead to poorer health overall. ${ }^{27,}{ }^{28}$ There is individual variation in psychosocial environments and McClintock et al., ${ }^{29}$ showed that this individual variation could contribute to methylation of cancer genes that are part of the ontogeny of malignant disease throughthe failure of tissue-specific programmed cell death.Moreover, Women of African-ancestry tend to be diagnosedwith more aggressive types of breast cancer, such as ER- (estrogen receptor negative) and ER-/PR-/HER2- (estrogen receptor negative, progesterone receptor negative, HER2 expression negative) breast cancer than populations of European-ancestry. ${ }^{30}$ Genome-wide association studies have also identified a few differences in breast cancer risk variants between populations of European and African ancestry. ${ }^{31,32}$ These features should be considered particularly in French Guiana where almost one third of people were born outside France and hadan African-ancestry.

One limitation of this paper is that we did not adjust the analyses based on HER2/neu expression becausesuch information was not available for most of the patients from the Registry database. This couldbe the focus of a future article becauseit deserves a thorough evaluation by itself.Another potential study limitation was that hormone receptor status, tumor histology and tumor grade were not assessed centrally becausethe data recorded by the cancer registry of French Guiana were derived from the review of clinical pathology reports from several hospitals. However, the proportions of the different hormone receptor status observed in our study were consistent with those reported in other studies. ${ }^{33}$

Many reports suggest less surgery, radiation therapy, and hormone treatment and sometimes inappropriate treatments among African American patients when compared with Caucasian patients. ${ }^{34}$ However, since delay of first treatment, type of treatment was unknown for too many women in the present study, this represents another limitation of the results. This could have resulted in some confounders not being accounted for in the model.

Despite somelimitations, the present study brings information on survival for clinically different subgroups of cancer patients. Thisimportant information on cancer survivalisof practical interest for health care planners and physicians. Our study underlines that access to care for migrants is challenging and leads tohealth inequalities. This observation comes at a moment when the French Ministry of Health has just released a Health law that places great emphasis on the reduction of health inequalities.Early detection through optimized prevention programs is crucial for increasing breast cancer survival, notably for foreign-born patients who represent a significant proportion of the population in French Guiana. The present results should thus stimulate further research to disentangle the main actionable determinants behind these survival differences.

\section{CLINICAL PRACTICE POINTS}

- Some studies showed that being of immigrant origin was a risk factor for being screened for cancer too late or never.

- However, based on ethical and ideological considerations, the mortality of immigrants in France has been scarcely studied.

- Our study showed a statistically significant difference in breast cancer survival between women in French Guiana according to their immigrant status.

- The data suggest that physicians and health care plannersshould consider targeting particular vulnerable subgroups of women for appropriate treatment, medical follow-up, and generally for culturally appropriate screening campaigns.

\section{ACKNOWLEDGEMENTS}

The authors thank Professor J.P. Droz for a critical reading of themanuscript.We certify that there is no conflict of interest with any financial organization regarding the material discussed in the manuscript.The present study was funded by the Health Regional Agency of French Guiana. The funders had no role in study design, data collection and analysis, decision to publish, or preparation of the manuscript.

Competing interests: All authors declare: no support from any organisation for the submitted work; no financial relationships with any organisations that might have an interest in the submitted work in the previous three years; no other relationships or activities that could appear to have influenced the submitted work. 


\section{REFERENCES}

1. Parkin DM, Pisani P, Ferlay J. Global cancer statistics. CA Cancer J Clin. 1999;49:33-64, 31.

2. Schwartsmann G. Breast cancer in South America: challenges to improve early detection and medical management of a public health problem. J Clin Oncol. 2001;19:118S-124S.

3. GLOBOCAN 2012: Estimated Cancer Incidence, Mortality and Prevalence Worldwide in 2012. IARC. Section of cancer information: IARC; 2014.

4. Roue T, Fior A, Plenet J, Belliardo S, Nacher M. The epidemiology of breast cancer in French Guiana 2003-2006. Springerplus. 2013;2:471.

5. Ruder AM, Lubin F, Wax Y, Geier A, Alfundary E, Chetrit A. Estrogen and progesterone receptors in breast cancer patients. Epidemiologic characteristics and survival differences. Cancer. 1989;64:196202.

6. Holleczek B, Jansen L, Brenner H. Breast cancer survival in Germany: a population-based high resolution study from Saarland. PloS one. 2013;8:e70680.

7. Nystrom L, Andersson I, Bjurstam N, Frisell J, Nordenskjold B, Rutqvist LE. Long-term effects of mammography screening: updated overview of the Swedish randomised trials. Lancet. 2002;359:909919.

8. de Koning HJ. Mammographic screening: evidence from randomised controlled trials. Annals of oncology : official journal of the European Society for Medical Oncology / ESMO. 2003;14:1185-1189.

9. Autier P, Boniol M, La Vecchia C, et al. Disparities in breast cancer mortality trends between 30 European countries: retrospective trend analysis of WHO mortality database. BMJ. 2010;341:c3620.

10. Ryu SY, Crespi CM, Maxwell AE. What factors explain disparities in mammography rates among Asian-American immigrant women? A population-based study in California. Women's health issues : official publication of the Jacobs Institute of Women's Health. 2013;23:e403-410.

11. Consedine NS. The demographic, system, and psychosocial origins of mammographic screening disparities: prediction of initiation versus maintenance screening among immigrant and non-immigrant women. Journal of immigrant and minority health / Center for Minority Public Health. 2012;14:570582.

12. Rondet C, Lapostolle A, Soler M, Grillo F, Parizot I, Chauvin P. Are immigrants and nationals born to immigrants at higher risk for delayed or no lifetime breast and cervical cancer screening? The results from a population-based survey in Paris metropolitan area in 2010. PloS one. 2014;9:e87046.

13. INSEE. 2014.

14. Norredam M, Olsbjerg M, Petersen JH, Hutchings M, Krasnik A. Cancer mortality does not differ between migrants and Danish-born patients. Danish medical journal. 2014;61:A4848.

15. an der Heiden M. Sata module to perform capture-recapture analysis for three sources with Goodnessof-fit based confidence intervals2009.

16. Jooste V, Grosclaude P, Remontet L, et al. Unbiased estimates of long-term net survival of solid cancers in France. Int J Cancer. 2013;132:2370-2377.

17. Corazziari I, Quinn M, Capocaccia R. Standard cancer patient population for age standardising survival ratios. Eur J Cancer. 2004;40:2307-2316.

18. Hess KR. Assessing time-by-covariate interactions in proportional hazards regression models using cubic spline functions. Stat Med. 1994;13:1045-1062.

19. Royston P. Multiple imputation of missing values: further update of ice, with an emphasis on interval censoring. The Stata Journal. 2007;4:445-464.

20. White IR, Royston P, Wood AM. Multiple imputation using chained equations: Issues and guidance for practice. Stat Med. 2011;30:377-399.

21. Li CI. Risk of mortality by histologic type of breast cancer in the United States. Hormones \& cancer. 2010;1:156-165.

22. Dunnwald LK, Rossing MA, Li CI. Hormone receptor status, tumor characteristics, and prognosis: a prospective cohort of breast cancer patients. Breast cancer research : BCR. 2007;9:R6.

23. Smith RE, Good BC. Chemoprevention of breast cancer and the trials of the National Surgical Adjuvant Breast and Bowel Project and others. Endocrine-related cancer. 2003;10:347-357. 
24. Sant M, Allemani C, Capocaccia R, et al. Stage at diagnosis is a key explanation of differences in breast cancer survival across Europe. Int J Cancer. 2003;106:416-422.

25. Sant M. Differences in stage and therapy for breast cancer across Europe. Int J Cancer. 2001;93:894901.

26. Boulogne R, Jougla E, Breem Y, Kunst AE, Rey G. Mortality differences between the foreign-born and locally-born population in France (2004-2007). Soc Sci Med. 2012;74:1213-1223.

27. Ding H, Hargraves L. Stress-associated poor health among adult immigrants with a language barrier in the United States. Journal of immigrant and minority health / Center for Minority Public Health. 2009;11:446-452.

28. Chen WT. Chinese female immigrants english-speaking ability and breast and cervical cancer early detection practices in the New York metropolitan area. Asian Pacific journal of cancer prevention : APJCP. 2013;14:733-738.

29. McClintock MK, Conzen SD, Gehlert S, Masi C, Olopade F. Mammary cancer and social interactions: identifying multiple environments that regulate gene expression throughout the life span. The journals of gerontology. Series B, Psychological sciences and social sciences. 2005;60 Spec No 1:32-41.

30. Long J, Zhang B, Signorello LB, et al. Evaluating genome-wide association study-identified breast cancer risk variants in African-American women. PloS one. 2013;8:e58350.

31. Feng Y, Stram DO, Rhie SK, et al. A comprehensive examination of breast cancer risk loci in African American women. Human molecular genetics. 2014;23:5518-5526.

32. Olopade OI, Fackenthal JD, Dunston G, Tainsky MA, Collins F, Whitfield-Broome C. Breast cancer genetics in African Americans. Cancer. 2003;97:236-245.

33. Bhikoo R, Srinivasa S, Yu TC, Moss D, Hill AG. Systematic review of breast cancer biology in developing countries (part 1): Africa, the middle East, eastern europe, Mexico, the Caribbean and South america. Cancers. 2011;3:2358-2381.

34. Li CI, Malone KE, Daling JR. Differences in breast cancer stage, treatment, and survival by race and ethnicity. Arch Intern Med. 2003;163(1):49-56. 